Wilfrid Laurier University

Scholars Commons @ Laurier

2005

\title{
A longitudinal study of phonological processing skills and reading in bilingual children
}

Alexandra Gottardo

Wilfrid Laurier University, agottard@wlu.ca

Adèle Lafrance

University of Toronto

Follow this and additional works at: https://scholars.wlu.ca/psyc_faculty

\section{Recommended Citation}

Gottardo, Alexandra and Lafrance, Adèle, "A longitudinal study of phonological processing skills and reading in bilingual children" (2005). Psychology Faculty Publications. 2.

https://scholars.wlu.ca/psyc_faculty/2

This Article is brought to you for free and open access by the Psychology at Scholars Commons @ Laurier. It has been accepted for inclusion in Psychology Faculty Publications by an authorized administrator of Scholars Commons@Laurier. For more information, please contact scholarscommons@wlu.ca. 


\title{
A longitudinal study of phonological processing skills and reading in bilingual children
}

\author{
ADÈLE LAFRANCE \\ Ontario Institute for Studies in Education of the University of Toronto
}

\author{
ALEXANDRA GOTTARDO \\ Wilfrid Laurier University
}

\author{
ADDRESS FOR CORRESPONDENCE \\ Adèle Lafrance, Human Development and Applied Psychology, Ontario Institute for Studies \\ in Education of the University of Toronto, Toronto, Ontario, M5S 1V6, Canada. \\ E-mail: alafrance@oise.utoronto.ca
}

\begin{abstract}
French/English bilingual children $(N=40)$ in French language schools participated in an 8-month longitudinal study of the relation between phonological processing skills and reading in French and English. Participants were administered measures of phonological awareness, working memory, naming speed, and reading in both languages. The results of the concurrent analyses show that phonological awareness skills in both French and English were uniquely predictive of reading performance in both languages after accounting for the influences of cognitive ability, reading ability, working memory, and naming speed. These findings support the hypothesis that phonological awareness is strongly related to beginning word reading skill in an alphabetic orthography. The results of the longitudinal analyses also suggest that orthographic depth influences phonological factors related to reading.
\end{abstract}

Over the past two decades researchers have determined that phonological processing skills are related to reading (Bruck, 1992; Rack, Hulme, Snowling, \& Wightman, 1994; Stanovich \& Siegel, 1994). However, the nature of the relationships among phonological subprocesses and their relative contribution to reading continue to be investigated. One theoretical framework identifies phonological awareness, phonological processing in verbal working memory, and phonological access in lexical memory as three phonological processing skills related to reading performance in monolingual English speakers (Bruck \& Genesee, 1995; Gough, Ehri, \& Treiman, 1992; Wagner \& Torgesen, 1987; Wagner, Torgesen, Laughon, Simmons, \& Rashotte, 1993). Recently, studies have shown that phonological processing skills are also related to second language (L2) reading performance (Comeau, Cormier, Grandmaison, \& Lacroix, 1999; Durgunoglu, 2002; Durgunoglu, Nagy, \& Hancin-Bhatt, 1993; Geva \& Wang, 2001; Gottardo, Yan, Siegel, \& Wade-Woolley, 2001; Wade-Woolley, 1999). The current study examined the role of the three phonological processing skills in first language

(C) 2005 Cambridge University Press 0142-7164/05 \$12.00 
Lafrance \& Gottardo: Study of phonological processing skills and reading

(L1) and L2 reading both across and within languages in French-English bilingual children.

\section{PHONOLOGICAL PROCESSES AND READING PERFORMANCE IN THE L1}

The first and most developed construct of phonological processing is phonological awareness, which includes the reader's awareness of the sound structure of the language (McBride-Chang, 1995). This skill has consistently been associated with reading in the L1 (Share \& Stanovich, 1995; Stanovich \& Siegel, 1994). In relation to early reading acquisition, phonological recoding, which is related to phonological awareness, is considered by some to be the sine qua non of reading acquisition (Share, 1995). However, phonological awareness may be reciprocally related to reading skill (Morais, Alegria, \& Content, 1987; Perfetti, 1985; Wagner, Torgesen, \& Rashotte, 1994) with different levels of phonological awareness being differentially related to reading acquisition and development (Snow, Burns, \& Griffin, 1999; Stanovich, Cunningham, \& Cramer, 1984; Wagner \& Torgesen, 1987; Yopp, 1988). For example, lower level phonological awareness skills such as onset-rime awareness are prerequisites of reading acquisition (Goswami \& Mead, 1992; Stuart \& Coltheart, 1988), while higher level skills such as full phoneme awareness are enhanced by exposure to print (Ehri, 1998; Perfetti, 1985). Early phonological awareness training also facilitates reading acquisition (Bradley \& Bryant, 1983; Hatcher, Hulme, \& Snowling, 2004; Lundberg, Frost, \& Petersen, 1988; Schneider, Roth, \& Ennemoser, 2000) and may be causally related to reading. Phonological awareness is often considered an explicit phonological process because it requires conscious manipulation of phonological components of speech (Gombert, 1992).

The second construct involved in the processing of information is related to phonological access in lexical memory. It may be specifically related to access of phonological information or related to the links between phonological and orthographic processing. This construct is considered by some researchers to be associated with speed of lexical access, or naming speed (Chiappe, Stringer, Siegel, \& Stanovich, 2002; Wagner et al., 1994) or to include a broader construct involving speed of access to information in any form (Bowers \& Wolf, 1993).

The third construct is centered on phonological processing in verbal working memory and involves holding information in working memory for later synthesis into sentences or into words (Baddeley, Lewis, \& Vallar, 1984). It has been theorized that phonological information, such as sound units, is retained in working memory by continuous repetition through an articulatory loop (Baddeley, 1979). Phonological working memory in prereaders is associated with reading skill in beginning readers (Gathercole \& Baddeley, 1990). Both naming speed and working memory are considered implicit phonological processes because they are cognitive processes that unconsciously involve speech codes (Gombert, 1992).

For monolingual English speakers, each of the phonological processing skills appears to explain both common and unique variance in word reading, with different studies providing differing accounts of overlap (Chiappe et al., 2002; Gottardo, Stanovich, \& Siegel, 1996; Manis, Seidenberg, \& Doi, 1999; 
McBride-Chang, 1995; Shankweiler, Crain, Brady, \& Macaruso, 1992). Wagner and Torgesen (1987) found the different processing skills to be somewhat related to each other. However, Mann (1984) studied the relationships between the measures representing the different processing skills and found that the correlations were nonsignificant, therefore indicating their independence. Despite these findings, each phonological processing skill was found to have varying levels of statistically predictive power on word reading performance. Phonological awareness was the most reliable predictor of word reading performance, followed by phonological processing in verbal working memory (herein referred to as working memory) and phonological access in lexical memory (herein referred to as naming speed) (Bowers, 1995; Bowers \& Wolf, 1993; Mann, 1984; Wagner et al., 1994).

\section{PHONOLOGICAL PROCESSES AND READING IN THE L2}

Research conducted with bilingual readers examining the relative contributions of all three phonological processing constructs is sparse. In 1993, Durgunoglu et al. examined the relationships between phonological awareness and reading in native Spanish speakers learning English as an L2. They found that in Grade 1, phonological processing skills in both the L1 and the L2 correlated with L2 word recognition. Further, children who had strong Spanish phonological awareness and word recognition skills performed much better when reading English words and English-like pseudowords than did children who had weak Spanish phonological awareness and word recognition skills. Subsequent research has demonstrated that one subcomponent of phonological processing, phonological awareness, is consistently related to L2 reading (see Durgunoglu, 2002, and Geva \& Wang, 2001, for reviews).

Both English phonological awareness and naming speed skills are lower in English as a second language (ESL) kindergarten children compared to their English as an L1 peers but ESL children make significant gains and their performance becomes equal to their L1 peers by Grade 2 (Lesaux \& Siegel, 2003). A comparison of the relative variance contributed by naming speed and phonological awareness in a diverse group of ESL speakers in Grades 1 and 2 revealed that phonological awareness contributed greater variance than naming speed (Geva, Yaghoub-Zadeh, \& Schuster, 2000). McBride-Chang and Kail (2002) examined naming speed and phonological awareness in Chinese speakers and ChineseEnglish bilinguals, and found that phonological awareness was strongly related to reading while speeded naming was weakly related to reading. The integrity of the phonological loop is associated with L2 skills, in particular, vocabulary acquisition (Service, 1992), but not necessarily word reading skill (Lindsey, Manis, \& Bailey, 2003). Studies that included all three phonological processing constructs support the finding that phonological awareness is the best predictor of word decoding ability within and across languages (Comeau et al., 1999; Lindsey et al., 2003).

Comeau and colleagues (1999) found evidence for cross-language transfer of the phonological processing skills and reading performance in children with English as L1 and French as L2. They showed that L1 phonological awareness skills transferred to L2 reading, thus providing more evidence in support of the 
Lafrance \& Gottardo: Study of phonological processing skills and reading

hypothesis that phonological processing skills transfer across languages. Moreover, the researchers found that the relationship between phonological awareness in both languages and L1 and L2 reading skills was equivalent. Similar findings regarding the transfer of phonological awareness skills exist in diverse languages such as Portuguese and English (DaFontoura \& Siegel, 1995) and Chinese and English (Gottardo et al., 2001).

Research on L2 reading acquisition introduces the debate as to whether linguistic processes are language universal or language specific. Underlying linguistic processing skills in an area such as phonology may transfer from the child's L1 to the child's L2. This positive transfer of skills across languages allows skills from one language to facilitate acquisition of skills in another language and suggests language universal processing mechanisms (Cummins, 1984, 1991). However, specific linguistic knowledge from the child's L1 may interfere with language development in the child's L2, suggesting language-specific processing skills. In addition, specific scripts may require slightly different reading strategies or be related to slightly different oral language and underlying processing skills (Geva \& Siegel, 2000).

The debate as to whether L1 processes interfere with or transfer in a positive manner to L2 processes has not been resolved. For example, L1 phonological knowledge interfered with phoneme identification in children learning Hebrew as an L2 (Wade-Woolley \& Geva, 2000) and spelling in Chinese ESL learners (Wang \& Geva, 2003). However, general phonological awareness skills are considered to transfer positively across languages, and are thought to be learned only once (Durgunoglu, 2002). Even among phonological awareness measures, the overlap between L1 and L2 phonological awareness performance is not perfect (Gottardo et al., 2001). In addition, the extent to which positive transfer occurs across the three phonological processes has not received much attention (Comeau et al., 1999). Finally, if phonological processing skills across languages are driven by one underlying process, then the relationships between L1 and L2 phonological processing and L1 and L2 reading are expected to be bidirectional.

To extend this line of research, the current study examined the longitudinal and concurrent relationships between L1 and L2 phonological processing and L1 and $L 2$ reading in French/English bilingual children schooled exclusively in the French language.

\section{ORTHOGRAPHIC DIFFERENCES BETWEEN FRENCH AND ENGLISH}

The degree of similarity between L1 and L2 phonology and orthography may affect the reading acquisition process (Geva \& Siegel, 2000; Geva \& WadeWoolley, 1998; Paulesu et al., 2001). Therefore, it is necessary to consider the orthographies of the French and English languages when comparing the relationships between phonological processes and reading. For example, although the French and English languages are both alphabetic, their orthographies are quite different. The French system is somewhat inconsistent with many silent letters, especially in word final position. It also has some syntactic marks that have no correspondence in speech. However, the English system is even more ambiguous with respect to the conversion of spelling to sound (Content, 1991). English is 
characterized as a quasiregular orthography with the regularity encoded at the level of the onset rime (Plaut, McClelland, Seidenberg, \& Patterson, 1996; Treiman, Mullennix, Bijeljac-Babic, \& Richmond-Welty, 1995; Venezky \& Massaro, 1987). In English, both word regularity and frequency influence reading performance (Seidenberg, Waters, Barnes, \& Tanenhaus, 1984). In French, word regularity has a strong influence on reading performance, while word frequency has a much smaller influence on reading performance (Ziegler, Perry, \& Coltheart, 2003). For these reasons, English is considered to have a deep alphabetic orthography, whereas French orthography is characterized as intermediate between shallow and deep. Spanish would represent a shallow orthography because of its language's consistent correspondence between letter and sound.

Additional factors such as the phonological and syllabic structure of the spoken language differ as well. For example, English is considered a stress-timed language while French is a syllable-timed language. These differences may affect the organization of phonological representations of words and the size of the unit that is most salient for reading acquisition. For example, French speakers use syllabic information to a greater extent in speech perception tasks while English speakers use phonemic information (Cutler, Mehler, Norris, \& Segui, 1986). In addition, monosyllabic words in French tend to have a consonant-vowel structure resulting in a simplified rime unit in comparison with English monosyllabic words, which often end in a consonant. Differences have been found when French speakers were compared to English speakers on several phonological tasks (Bruck, Genesee, \& Caravolas, 1997). French-speaking kindergarten children performed better on syllable awareness tasks while English-speaking children performed better on onset-rime and phoneme level tasks (Bruck et al., 1997).

Learning to read a more consistent orthography may require the use of different phonological processing skills (Goswami, 2002; Goswami, Ziegler, Dalton, \& Schneider, 2003; Wimmer, 1993; Wimmer, Mayringer, \& Landerl, 1998). For example, early in the reading acquisition process, reading fluency and naming speed, which are related to fluency, become better indicators of reading performance in languages with shallow orthographies such as Dutch and German (de Jong \& van der Leij, 2002; Wimmer, 1993). Jiménez-González (1997) hypothesized that phonemic awareness and letter-sound knowledge were sufficient skills to read a shallow orthography such as Spanish. Reading and spelling acquisition in French is also related to the use of phonological mediation (Sprenger-Charolles \& Casalis, 1995; Sprenger-Charolles \& Siegel, 1997; Sprenger-Charolles, Siegel, \& Bonnet, 1998). According to Seymour, Aro, and Erskine (2003), the rate of reading development in English is more than twice as slow as in the more shallow orthographies such as French and Dutch. They hypothesize that the deeper orthographies involve the implementation of logographic and alphabetic foundations, which take more than twice as long to establish as the single alphabetic foundation required for the learning of a more shallow orthography. In addition, most models of reading acquisition that are based on English include an orthographic phase (Chall, 1983; Ehri, 1997; Frith, 1986). Research comparing reading acquisition in French speakers and English speakers showed that the French group made greater gains in reading despite lower initial prereading skills (Bruck et al., 1997). 


\section{PURPOSE OF STUDY}

This study investigated a series of longitudinal relationships between phonological processing skills (phonological awareness, naming speed, and working memory) and word reading from kindergarten to Grade 1 in bilingual French/English children enrolled in French language schools. This design allowed the examination of the degree of relationships between the following:

1. phonological processing skills in L1 (French) and word reading in L1,

2. phonological processing skills in L1 and word reading in L2 (English),

3. phonological processing skills in $\mathrm{L} 2$ and word reading in $\mathrm{L} 1$, and

4. phonological processing skills in $\mathrm{L} 2$ and word reading in $\mathrm{L} 2$.

Our study also allowed for the examination of the concurrent relationships between phonological processing and word reading performance in Grade 1. All relationships were examined using a measure of nonverbal reasoning ability as a control variable.

Two hypotheses were tested. The first hypothesis predicts there will be crosslanguage transfer of phonological processing skills, and that phonological processing in one language will be related to reading in the other language. This hypothesis is based on literature examining transfer of L1 phonological processing to L2 reading. It incorporates the work of Durgunoglu (2002), who believes that phonological processes such as phonological awareness need only be acquired once in one of the child's languages to transfer. This examination of bidirectional transfer of phonological processing skills across L1 and L2 is not common in the literature, which usually examines L1 effects on L2 processing. However, the investigation of bidirectional transfer across L1 and L2 addresses whether phonological processing skills are driven by underlying processes that are language general or language specific. The second hypothesis, which is related to extensive previous research (see Snow et al., 1999, for a review), predicts that phonological awareness will be the most important longitudinal and concurrent predictor of word reading performance.

\section{METHOD}

\section{Participants}

All children were recruited from primary schools in southern Ontario in the spring of 2002. Instruction in all of the schools was delivered exclusively in the French language. Although only children with at least one parent who is a native French speaker are allowed to enroll in these French language schools, the children live in a predominantly English-speaking environment, resulting in a balanced bilingual profile. However, only children with at least one parent who spoke French in the home were invited to participate. The majority of the children had French as their L1 and English as their L2 as indicated by interviews with teachers and principals. Questions also accompanied the consent form inquiring about the languages spoken in the home, and all children were reported to speak French. 
Forty children participated in the study ( 23 boys, 17 girls). All children were first tested in May of their senior kindergarten year, which is the first year of compulsory schooling in Ontario. It should be noted that in senior kindergarten, there is no formal reading instruction. The mean age of the children was 5 years and 9 months ( $S D=4$ years, 10 months). In January of Grade 1, the children were tested for a second time.

\section{MATERIALS}

\section{$L 1$ and $L 2$ word reading}

English word reading was measured using the Word Identification and the Word Attack subtests of the Woodcock Reading Mastery Test-Revised (WRMTR; Woodcock, 1987). French word reading was measured using experimental word and pseudoword lists that paralleled the WRMT-R. All tasks showed high internal consistency reliability ranging from .92 to .98 . For all measures of word reading the child read single words (or pseudowords) that were presented on flash cards. A ceiling of six consecutive items was used for the English tasks and the French word reading task. A ceiling of four items in a set of eight items was used for the French pseudoword task. For both French and English measures, the total number of correct responses corresponded to the child's score. Scores for both senior kindergarten and Grade 1 reading and pseudoword reading in each language were combined and used as dependent variables.

\section{$L 1$ and $L 2$ measures of phonological processing}

Phonological awareness. The Auditory Analysis Test (Rosner \& Simon, 1971) and its French version (Test d'Analyse Auditive en Français [TAAF]; Cormier, MacDonald, Grandmaison, \& Ouellette-Lebel, 1995) were administered to the children. The Auditory Analysis Test consists of three training items and 40 test items, and the TAAF consists of four training items and 42 test items. Both tests have the same types of auditory deletion items and showed high internal consistency reliability coefficients of .92 and .94 , respectively. For both tasks, the child was asked to delete a syllable in a two-syllable word (e.g., say toothbrush without /tooth/), delete the first consonant of a single syllable word (e.g., say sat without the $/ \mathrm{s} /$ ), delete the last consonant of a single syllable word (e.g., say rode without the $/ \mathrm{d} /$ ), delete the first consonant of a consonant cluster (e.g., say smile without the $/ \mathrm{s} /$ ), delete a consonant inside a word (e.g., say smell without the $/ \mathrm{m} /$ ), and delete the middle syllable in a word containing at least three syllables (e.g., say dynamo without the /na/). The score obtained by the child corresponded to the total number of correct responses. A ceiling of five consecutive errors was used for both versions of the task.

Rhyme-based and phoneme-based phonological awareness. Phonological awareness at the onset-rime level was measured using rhyme detection tasks and phoneme detection tasks in each of the languages (adapted from Stanovich, 
Lafrance \& Gottardo: Study of phonological processing skills and reading

Cunningham, \& Cramer, 1984). For the rhyme detection task, the child was individually presented with 3 sets of practice stimuli followed by all 15 sets of test stimuli. The stimuli consisted of three words in which the word that did not rhyme with the others was to be identified. For example, the experimenter said, "If I say ring, sing, and dog," which one doesn't rhyme?" If necessary, the child was permitted to ask for repetitions, and was presented with only three words to reduce the memory load for the task (Gottardo et al., 2001). The score obtained by the child corresponded to the total number of correct responses and the highest possible score for both tasks in each language was 15. The English and French rhyme detection tasks yielded internal consistency reliability coefficients of .85 and .86 , respectively.

Similarly, for the phoneme detection task, the child was presented with one practice trial followed by all 15 test stimuli. The stimuli consisted of three words in which the word that started with a different sound was to be identified. For example, the experimenter said, "If I say bag, nine and ball, which one starts with a different sound?" The score obtained by the child corresponded to the total number of correct responses and the highest possible score was 15. Internal consistency reliability coefficients for the English and French phoneme detection tasks were .81 and .85 , respectively.

To encompass all levels of phonological awareness, scores on all three measures of phonological awareness were combined and used in the reported analyses.

Naming speed. Based on the Rapid Automatic Naming Test (RAN; Denckla \& Rudel, 1974), the standardized automatic naming subtest of the Comprehensive Test of Phonological Processing was administered in English to measure naming speed (Wagner et al., 1999). A French translation using identical stimuli was also administered. Both color-naming and digit-naming measures were administered. The child was required to name, from left to right, digits or colors presented in an $8 \times 4$ array. All response times were recorded with a stopwatch, and the child was encouraged to name the stimuli as quickly and as carefully as possible. This task was scored in terms of naming time (in seconds) in addition to the number of uncorrected errors. Reliability coefficients for the RAN were not possible to determine because of the administration and scoring methods used. However, Wagner et al. (1994) administered a similar task with digits and obtained a splithalf reliability coefficient of .91 after Spearman-Brown correction. A combined score for both the rapid naming of digits and colors was computed and used in the reported analyses.

Working memory. The Digits Backward subtest of the Wechsler Intelligence Scale for Children-Third Edition was used to measure working memory in English (Wechsler, 1991). The subtest was translated into French and administered to the children. The experimenter read a series of digits ranging from two to eight items in length, and the child was required to repeat this series, but in reverse order. For example, if the experimenter said "two (pause) nine," the correct answer was nine, two. If the child made two consecutive errors within a set, the administration of the test was discontinued. The score obtained by the child 
Lafrance \& Gottardo: Study of phonological processing skills and reading

Table 1. Means and standard deviations of the exemplar variables across time

\begin{tabular}{|c|c|c|c|c|c|}
\hline \multirow[b]{2}{*}{ Variables } & \multicolumn{2}{|c|}{$\begin{array}{c}\text { Senior } \\
\text { Kindergarten }\end{array}$} & \multicolumn{2}{|c|}{ Grade 1} & \multirow[b]{2}{*}{$T$ Value } \\
\hline & $M$ & $S D$ & $M$ & $S D$ & \\
\hline \multicolumn{6}{|l|}{ L1 } \\
\hline Word reading & 7.88 & 10.99 & 33.30 & 20.51 & $-9.69^{* *}$ \\
\hline Phonological awareness & 25.53 & 13.54 & 33.85 & 11.74 & $-6.73^{* *}$ \\
\hline Naming speed & 73.80 & 34.31 & 77.57 & 15.90 & 2.33 \\
\hline Working memory & 2.33 & 1.00 & 2.73 & 0.97 & $-2.45^{*}$ \\
\hline \multicolumn{6}{|l|}{$\mathrm{L} 2$} \\
\hline Word reading & 8.20 & 17.57 & 14.03 & 21.10 & $-3.26^{* *}$ \\
\hline Phonological awareness & 33.80 & 14.12 & 32.08 & 12.55 & 2.08 \\
\hline Naming speed & 89.78 & 28.37 & 79.24 & 23.39 & $1.14^{*}$ \\
\hline Working memory & 2.58 & 1.26 & 2.72 & 0.94 & -0.66 \\
\hline
\end{tabular}

${ }^{*} p<.05{ }^{* *} p<.01$.

corresponded to the total number of correct responses and the highest possible score was 14.

\section{Measure of nonverbal reasoning}

Nonverbal reasoning ability. The Matrix Analogies Test (MAT) was used to measure nonverbal reasoning ability (Naglieri, 1985). The MAT was selected as means of assuring that all participants were functioning in the average range. The participants were asked to point to the items in an array of five to six abstract designs that best completed the patterns comprising one large design or four to nine smaller related designs.

\section{Procedure}

In senior kindergarten, all children received an individually administered battery of tests in their L1 and their L2 measuring phonological processing skills, word reading performance, and nonverbal reasoning. The test administration was completed over two sessions, one for each language, and the order was counterbalanced. In Grade 1, the children were administered the same battery of tests with the exception of nonverbal reasoning. All participants were individually tested in their respective schools during school hours by trained experimenters. Testing was divided into sessions lasting roughly $30 \mathrm{~min}$.

\section{RESULTS}

\section{Descriptive statistics}

Table 1 displays the means and standard deviations for all phonological processing tasks and reading tasks in senior kindergarten and Grade 1. Significant 
Table 2. Bivariate correlations among the primary variables and reading at Time 1 and Time 2

\begin{tabular}{lcc}
\hline \hline & L1 Reading (Grade 1) & L2 Reading (Grade 1) \\
\hline & Senior Kindergarten Measures & \\
Nonverbal reasoning & .35 & .35 \\
L1 & $.44^{*}$ & $.43^{*}$ \\
Working memory & $-.60^{*}$ & -.39 \\
Naming speed & $.64^{*}$ & $.58^{*}$ \\
Phonological awareness & $.51^{*}$ & $.54^{*}$ \\
L2 & $-.57^{*}$ & $-.46^{*}$ \\
Working memory & $.73^{*}$ & $.59^{*}$ \\
Naming speed & & \\
Phonological awareness & &
\end{tabular}

Grade 1 Measures

\begin{tabular}{lcc}
\hline L1 & & \\
Working memory & .23 & .18 \\
$\quad$ Naming speed & $-.55^{*}$ & $-.45^{*}$ \\
Phonological awareness & $.87^{*}$ & $.74^{*}$ \\
L2 & .17 & .27 \\
$\quad$ Working memory & $-.63^{*}$ & $-.51^{*}$ \\
Naming speed & $.78^{*}$ & $.75^{*}$ \\
Phonological awareness & \\
\hline \hline
\end{tabular}

${ }^{*} p<.01$.

gains over time were found for $\mathrm{L} 1$ reading, $t(1,39)=-9.69, p<.01, \mathrm{~L} 1$ phonological awareness, $t(1,39)=-6.96, p<.01$, L1 working memory, $t(1,39)=-2.45, p<.05, \mathrm{~L} 2$ naming speed, $t(1,35)=2.69, p<.01$, and L2 word reading, $t(1,39)=-3.26, p<.01$. A closer examination of the distributional properties of the tasks indicated several problems. For example, performance on reading and some phonological awareness measures was positively skewed with many children having very low scores. As a result, log transformations were performed on the skewed variables, and only the log-transformed scores were used in the subsequent analyses. ${ }^{1}$ One of the participants was reading well above level in French and English in kindergarten. The regression analyses were also conducted excluding his score. However, the results of the analyses remained the same therefore his data was retained for all the analyses.

\section{Analysis of longitudinal and concurrent bivariate correlations among the primary variables}

Bivariate correlational analyses were conducted using the scores on the measures of nonverbal reasoning, word reading, and phonological processing (Table 2). The 
Lafrance \& Gottardo: Study of phonological processing skills and reading

results of these correlational analyses showed that longitudinally and concurrently, L1 and L2 phonological awareness, showed the strongest correlations with L1 and L2 reading $r$ values $(40)=.58-.87$, followed by naming speed, $r$ values $(40)=$ $-.39-.63$. Working memory in senior kindergarten showed significant correlations to Grade 1 reading, $r$ values $(40)=.43-.54$, but concurrent correlations in Grade 1 were not significant.

\section{Longitudinal cross-language transfer of senior kindergarten phonological processing skills to word reading in Grade 1}

To examine the longitudinal relationships between phonological processing skills in senior kindergarten and reading performance in Grade 1, multiple regression analyses were conducted. The first regression model included nonverbal reasoning; the second model included nonverbal reasoning as Step 1 followed by senior kindergarten reading performance (as an autoregressor); the third model included nonverbal reasoning as Step 1, senior kindergarten reading performance as Step 2, and naming speed as Step 3; the fourth model included nonverbal reasoning as Step 1, senior kindergarten reading performance as Step 2, naming speed as Step 3, and working memory as Step 4; and the fifth model included nonverbal reasoning as Step 1, senior kindergarten reading performance as Step 2, naming speed as Step 3, working memory as Step 4, and phonological awareness as Step 5. The phonological processes were entered as separate steps as some degree of overlap was expected for the three variables. It was also expected that phonological awareness would be the only statistically significant variable if the three variables were entered in the same step. The results of the complete model (Model 5) were examined to determine which variables were significant when all five variables were entered in the regression equation.

Relationships between L1 phonological processing in senior kindergarten and reading in Grade 1. The first set of multiple regression analyses determined whether L1 phonological processing scores in senior kindergarten were statistically predictive of L1 and L2 word reading performance in Grade 1 (Table 3). The results showed that L1 word reading performance in Grade 1 was related to L1 naming speed, $\beta=-.370, t(5,35)=-2.75, p=.01$, and L1 phonological awareness, $\beta=.373, t(5,35)=2.77, p=.01$. No differences were found when working memory was entered before naming speed. However, the results of the regression analyses indicated that L2 word reading in Grade 1 was only related to $\mathrm{L} 1$ reading performance in senior kindergarten, $\beta=.487, t(5,35)=3.09$, $p<.01 .^{2}$

Relationships between L2 phonological processing in senior kindergarten and reading in Grade 1. The second set of multiple regression analyses determined which L2 phonological processing skills in senior kindergarten were related to L1 and L2 reading performance in Grade 1 (Table 3). The results showed that L1 word reading performance in Grade 1 was related to L2 phonological awareness in senior kindergarten, $\beta=.609, t(5,36)=2.81, p<.01$. When L2 working 
Lafrance \& Gottardo: Study of phonological processing skills and reading

Table 3. Hierarchical regression analyses examining the senior kindergarten predictors of word reading performance in Grade 1

\begin{tabular}{|c|c|c|c|c|c|c|c|}
\hline Model & Total $R^{2}$ & $\Delta R^{2}$ & $\begin{array}{c}\text { Nonverbal } \\
\text { Reasoning } \\
\quad(\beta)\end{array}$ & $\begin{array}{l}\text { SK Reading } \\
\text { Performance } \\
\qquad(\beta)\end{array}$ & $\begin{array}{c}\text { Average } \\
\text { Naming } \\
\text { Speed }(\beta)\end{array}$ & $\begin{array}{c}\text { Working } \\
\text { Memory } \\
(\beta)\end{array}$ & $\begin{array}{c}\text { Phonological } \\
\text { Awareness } \\
(\beta)\end{array}$ \\
\hline
\end{tabular}

L1 Phonological Processing Variables

\begin{tabular}{|c|c|c|c|c|c|c|c|}
\hline \multicolumn{8}{|c|}{ Grade 1 Word Reading L1 } \\
\hline 1 & .194 & .194 & $.441^{* *}$ & & & & \\
\hline 2 & .373 & .179 & .279 & $.452^{* *}$ & & & \\
\hline 3 & .512 & .139 & .110 & $.377^{* *}$ & $-.427^{* *}$ & & \\
\hline 4 & .517 & .005 & .110 & $.339^{*}$ & $-.406^{* *}$ & .553 & \\
\hline 5 & .615 & .098 & .108 & .217 & $-.370^{* *}$ & -.003 & $.373^{* *}$ \\
\hline \multicolumn{8}{|c|}{ Grade 1 Word Reading L2 } \\
\hline 1 & .160 & .160 & $.400^{*}$ & & & & \\
\hline 2 & .483 & .323 & .183 & $.608^{* *}$ & & & \\
\hline 3 & .499 & .176 & .126 & $.583^{* *}$ & -.144 & & \\
\hline 4 & .499 & .000 & .126 & $.571^{* *}$ & -.137 & .026 & \\
\hline 5 & .545 & .046 & .125 & $.487^{* *}$ & -.113 & -.034 & .256 \\
\hline
\end{tabular}

L2 Phonological Processing Variables

Grade 1 Word Reading L1

\begin{tabular}{lcccllll}
\hline 1 & .112 & .112 & $.335^{*}$ & & & \\
2 & .339 & .227 & .116 & $.525^{* *}$ & & \\
3 & .467 & .128 & -.002 & $.409^{* *}$ & $-.407^{* *}$ & & \\
4 & .473 & .006 & .008 & $.371^{*}$ & $-.353^{*}$ & .109 & $.609^{* *}$ \\
5 & .580 & .107 & -.057 & .095 & -.088 & .071 & \\
\hline \multicolumn{7}{c}{ Grade 1 Word Reading L2 } \\
\hline 1 & .109 & .109 & $.330^{*}$ & & & \\
2 & .678 & .569 & -.017 & $.831^{* *}$ & & \\
3 & .700 & .022 & -.065 & $.784^{* *}$ & -.166 & & \\
4 & .701 & .001 & -.059 & $.763^{* *}$ & -.137 & .058 & \\
5 & .703 & .002 & -.053 & $.792^{* *}$ & -.164 & .062 & -.064 \\
\hline \hline
\end{tabular}

${ }^{*} p<.05 .{ }^{* *} p<.01$.

memory was entered before naming speed, it accounted for significant variance in $\mathrm{L} 1$ reading $\beta=.333, t(5,36)=2.19, p<.05$, while $\mathrm{L} 1$ naming speed was only marginally related. However, the results of the regression analyses indicated that L2 word reading in Grade 1 was only related to L2 reading performance in senior kindergarten, $\beta=.792, t(5,36)=5.38, p<.01$. 


\section{Concurrent cross-language transfer of phonological processing skills to word reading in Grade 1}

To examine the relationships between phonological processing skills in Grade 1 and reading performance in Grade 1, multiple regression analyses were conducted. The first regression model included nonverbal reasoning; the second model included nonverbal reasoning as Step 1 followed by naming speed as Step 2; the third model included nonverbal reasoning as Step 1, naming speed as Step 2, and working memory as Step 3; and the fourth model included nonverbal reasoning as Step 1, naming speed as Step 2, working memory as Step 3, and phonological awareness as Step 4 . The results of the complete model (Model 4) were examined to determine which variables were significant when all four variables were entered in the regression equation.

Relationships between L1 phonological processing and reading in Grade 1. A first set of multiple regression analyses determined whether L1 phonological processing in Grade 1 was predictive of L1 and L2 word reading in Grade 1 (Table 4). The results showed that $\mathrm{L} 1$ word reading was significantly predicted by L1 phonological awareness skills, $\beta=.750, t(4,39)=7.32, p<.01$. The results of the multiple regression analyses also indicated that $\mathrm{L} 2$ word reading was significantly predicted by $\mathrm{L} 1$ phonological awareness, $\beta=.734, t(4,39)=5.34$, $p<.01$.

Relationships between L2 phonological processing and reading in Grade 1. A second set of multiple regression analyses determined whether L2 phonological processing in Grade 1 was predictive of L1 and L2 word reading in Grade 1 (Table 4). The results showed that $\mathrm{L} 1$ word reading was significantly predicted by L2 phonological awareness, $\beta=.661, t(4,35)=5.23, p<.01$, and L2 naming speed, $\beta=-.281, t(4,35)=-2.456, p<.05$. The results of the regression analyses also indicated that $\mathrm{L} 2$ word reading was significantly predicted by $\mathrm{L} 2$ phonological awareness, $\beta=.643, t(4,35)=4.43, p<.01$.

\section{Phonological awareness as the strongest concurrent and longitudinal predictor of word reading performance}

In addition to the fact that phonological awareness skills explained a unique portion of the variance in word reading over and above most of the other variables in longitudinal and concurrent test equations, the standardized regression coefficients for phonological awareness skills were the largest of the three phonological processing skills in seven of the eight testing situations. Therefore, the results of these analyses also support the hypothesis that phonological awareness in both languages is the strongest predictor of word reading among the three phonological processing skills.

\section{DISCUSSION}

The results of the comparisons on phonological measures suggest that the children in this sample performed at similar levels across languages even though French 
Lafrance \& Gottardo: Study of phonological processing skills and reading

Table 4. Hierarchical regression analyses examining the concurrent predictors of word reading performance in Grade 1

\begin{tabular}{|c|c|c|c|c|c|c|}
\hline Model & Total $R^{2}$ & $\Delta R^{2}$ & $\begin{array}{c}\text { Nonverbal } \\
\text { Reasoning } \\
\qquad(\beta)\end{array}$ & $\begin{array}{l}\text { Average } \\
\text { Naming } \\
\text { Speed }(\beta)\end{array}$ & $\begin{array}{c}\text { Working } \\
\text { Memory } \\
(\beta)\end{array}$ & $\begin{array}{c}\text { Phonological } \\
\text { Awareness } \\
(\beta)\end{array}$ \\
\hline \multicolumn{7}{|c|}{ L1 Phonological Processing Variables } \\
\hline \multicolumn{7}{|c|}{ Grade 1 Word Reading L1 } \\
\hline 1 & .168 & .168 & $.409^{* *}$ & & & \\
\hline 2 & .348 & .180 & $.302^{*}$ & $-.438^{* *}$ & & \\
\hline 3 & .357 & .009 & $.294^{*}$ & $-.440^{* *}$ & .096 & \\
\hline 4 & .746 & .389 & .103 & -.150 & -.051 & $.750^{* *}$ \\
\hline \multicolumn{7}{|c|}{ Grade 1 Word Reading L2 } \\
\hline 1 & .123 & .123 & $.351^{*}$ & & & \\
\hline 2 & .137 & .014 & $.321^{*}$ & -.121 & & \\
\hline 3 & .171 & .034 & .306 & -.125 & .183 & \\
\hline 4 & .543 & .372 & .120 & .159 & .040 & $.734^{* *}$ \\
\hline \multicolumn{7}{|c|}{ L2 Phonological Processing Variables } \\
\hline \multicolumn{7}{|c|}{ Grade 1 Word Reading L1 } \\
\hline 1 & .175 & .175 & $.419^{*}$ & & & \\
\hline 2 & .389 & .214 & .255 & $-.491^{* *}$ & & \\
\hline 3 & .408 & .019 & .228 & $-.494^{* *}$ & .141 & \\
\hline 4 & .686 & .278 & .054 & $-.281^{*}$ & -.066 & $.661^{* *}$ \\
\hline \multicolumn{7}{|c|}{ Grade 1 Word Reading L2 } \\
\hline 1 & .116 & .116 & $.340^{*}$ & & & \\
\hline 2 & .147 & .031 & .277 & -.187 & & \\
\hline 3 & .324 & .177 & .197 & -.196 & $.429^{* *}$ & \\
\hline 4 & .586 & .262 & .027 & .010 & .228 & $.643^{* *}$ \\
\hline
\end{tabular}

${ }^{*} p<.05 .{ }^{* *} p<.01$.

was their L1. The children had similar scores on tasks administered in French and English. Although all of the children were exposed to French at home, their greater exposure to English in the community and in childcare settings may have led to this result. When scores were compared over time, children showed gains from senior kindergarten to Grade 1 on most measures.

When relationships between the key phonological measures and reading were examined longitudinally, somewhat different patterns were found for predictors of L1 and L2 reading performance. For example, although senior kindergarten L1 
Lafrance \& Gottardo: Study of phonological processing skills and reading

and L2 phonological awareness skills predicted L1 reading performance in Grade 1 , early reading performance was the only predictor related to $\mathrm{L} 2$ reading.

The concurrent correlational data suggest that L1 phonological awareness and L2 phonological awareness were related to L1 and L2 reading in Grade 1. These findings are confirmed by the results of the hierarchical regression analyses that show that L1 and L2 phonological awareness in Grade 1 were the phonological processing variables that were uniquely predictive of $\mathrm{L} 1$ and $\mathrm{L} 2$ reading.

Our concurrent findings partially replicate the findings of Comeau and colleagues (1999) of cross-language transfer of phonological awareness in French and English and the unique predictive power of both L1 and L2 phonological awareness in French and English. However, in the previous study the children spoke English as their L1 and French as their L2 (Comeau et al., 1999). Our sample of bilingual French-English children spoke French as their L1 and was learning to read at school in their L1. However, they were highly proficient in English, their L2, and were concurrently learning to read in English through incidental exposure to written English. Our results also extend previous findings to a younger group of bilingual children who are beginning readers.

Naming speed in kindergarten was significantly related to L1 reading in Grade 1. This result was only found within language, and across time for L1 reading. The lack of a relationship between L2 reading and naming speed is different from the findings of Geva et al. (2000), but it might be explained by the strength of the autoregressor in the analyses examining L 2 reading. Geva and colleagues did not include an autoregressor in their analyses. Previous research with monolingual English speakers also found longitudinal relationships between naming speed and reading (Parrila, Kirby, \& McQuarrie, 2004). Although Grade 1 phonological awareness was related to early reading skills in another longitudinal study, early naming speed was found to be predictive of later reading skills (Kirby, Parrila, \& Pfeiffer, 2003).

The autoregressor was highly related to English reading skill but not French reading skill. This result can be interpreted based on the regularity of the two languages. English is a quasiregular language with consistency at the level of the rime. Orthographic knowledge is related to reading skill (Barker, Torgesen, \& Wagner, 1992; Cunningham, Perry, \& Stanovich, 2001), and stage theories of reading acquisition in English include an orthographic phase (Chall, 1983; Ehri, 1997; Frith, 1986). Orthographic knowledge is believed to be in part the result of reading experience or exposure to print (Cunningham \& Stanovich, 1991, 1997, 1998). For example, Grade 1 English reading skill is related to reading skill in Grade 4 (Juel, 1988).

In contrast, French is a more regular language (Ziegler et al., 2003). Therefore, underlying phonological processes, in particular phonological awareness, are more likely to be related to reading development. Sprenger-Charolles et al. (1998) found that young monolingual French speakers relied on phonological strategies to read and spell. This strong relationship between phonological awareness and reading has been reported in highly regular languages such as Spanish (JiménezGonzález, 1997). In addition, naming speed is more strongly related to reading performance in a more regular and consistent orthography (Wimmer, 1993). Our study shows different longitudinal predictors of reading skill across languages in 
the same children, suggesting that the nature of the orthography in part drives the processing skills related to reading.

Our results address the concept of cross-language transfer of phonological processing and the unique relationship between reading and phonological awareness. These findings are documented concurrently and longitudinally within the L1. This study found that phonological awareness in each language was related to both L1 and L2 reading. These findings support a strong link between L1 and L2 phonological processing and reading (Comeau et al., 1999; Durgunoglu, 2002; Durgunoglu et al., 1993; Geva \& Wang, 2001), which suggests that this skill may be universal across languages and may only need to be acquired once (Durgunoglu, 2002; Geva \& Siegel, 2000). Our findings also support the link between phonological awareness in both the child's L1 and L2, and reading ability in both languages (Durgunoglu, 2002; Gottardo et al., 2001). Given the model that phonological awareness is universal, once acquired, phonological awareness skills will influence reading development across languages and should transfer in a bidirectional manner. These findings suggest that phonological awareness is universally related to learning to read in an alphabetic language (Durgunoglu, 2002; Goswami, 2002). However, additional factors related to reading may be a function of the depth of the orthography.

The strength of our research is that the relationships are longitudinal, and that initially phonological processing skills were measured when the children were in kindergarten when they were nonreaders or beginning readers. Therefore, the effects of formal reading instruction were minimized (Morais, Alegria, \& Content, 1987; Perfetti, 1985).

These results with bilingual speakers are also commensurate with research conducted with monolingual speakers, which has found that phonological awareness is uniquely related to reading ability (Gottardo et al., 1996; Hulme, Hatcher, Nation, Brown, Adams, \& Stuart, 2002; Share, 1995; Stanovich \& Siegel, 1994) even when all other phonological measures were included in the analyses (Torgesen, Wagner, Rashotte, Burgess, \& Hecht, 1997). Therefore, phonological awareness is uniquely related to word reading skill in an alphabetic orthography in children. Orthographic depth appears to play a role in terms of additional factors related to reading. Our findings are also congruent with the research of Geva and Siegel (2000). They found support for the central processing hypothesis that suggests that specific cognitive and linguistic processes, such as phonological awareness, transfer across languages, and are basic to reading in any language. They also found support for language-specific explanations of reading development that suggest that the script of a language can be used to explain relationships between reading and underlying processing skills (Geva \& Siegel, 2000).

\section{ACKNOWLEDGMENTS}

We thank our colleagues Eileen Wood and Patricia Bowers, who read and provided feedback on earlier versions of this paper, as well as three anonymous reviewers. We also thank Mahboobeh Abdollahi, Jodie Allen, Jennifer Bernier, Yan Gu, Meghan Kenny, Kelly Sweeney-Fenn, Sandy Hitchcock, Hui Pan, and Melanie Webb for their help with the data collection. Finally, we are grateful to the Conseil Scolaire de District de Centre-Sud-Ouest, 
Lafrance \& Gottardo: Study of phonological processing skills and reading

the Conseil Scolaire de District Catholique Centre-Sud, and the students and staff in the schools for their cooperation and participation in the study. This research was supported in part by the Canadian Language and Literacy Research Network (CLLRNet).

\section{NOTES}

1. These variables included L1 and L2 reading, phonological awareness, and naming speed in kindergarten and Grade 1.

2. All of the analyses yielded similar results when performed using within and across language reading performance as the autoregressor.

\section{REFERENCES}

Baddeley, A. D. (1979). Working memory and reading. In P. A. Kolers, M. E. Wrolstad, \& H. Bouma (Eds.), Processing of visible language (pp. 355-370). New York: Plenum Press.

Baddeley, A., Lewis, V., \& Vallar, G. (1984). Exploring the articulatory loop. The Quarterly Journal of Experimental Psychology, 36, 233-252.

Barker, T. A., Torgesen, J. K., \& Wagner, R. K. (1992). The role of orthographic processing skills on five different reading tasks. Reading Research Quarterly, 27, 334-345.

Bowers, P. G. (1995). Tracing symbol naming speed's unique contributions to reading disabilities over time. Reading and Writing: An Interdisciplinary Journal, 7, 189-216.

Bowers, P. B., \& Wolf, M. (1993). Theoretical links among naming speed, precise timing mechanisms and orthographic skill in dyslexia. Reading and Writing, 5, 69-85.

Bradley, L., \& Bryant, P. (1983). Categorizing sounds and learning to read: A causal connection. Nature, 301, 419-421.

Bruck, M. (1992). Persistence of dyslexics' phonological awareness deficits. Developmental Psychology, 28, 874-886.

Bruck, M., \& Genesee, F. (1995). Phonological awareness in young second language learners. Journal of Child Language, 22, 307-324.

Bruck, M., Genesee, F., \& Caravolas, M. (1997). A cross-linguistic study of early literacy acquisition. In B. Blachman (Ed.), Foundations of reading acquisition and dyslexia: Implications for early intervention (pp. 163-189). Mahwah, NJ: Erlbaum.

Chall, J. S. (1983). Stages of reading development. New York: McGraw-Hill.

Chiappe, P., Stringer, R., Siegel, L. S., \& Stanovich, K. E. (2002). Why the timing deficit hypothesis does not explain reading disability in adults. Reading \& Writing, 15, 73-107.

Comeau, L., Cormier, P., Grandmaison, É., \& Lacroix, D. (1999). A longitudinal study of phonological processing skills in children learning to read in a second language. Journal of Educational Psychology, 91, 29-43.

Content, A. (1991). The effect of spelling-to-sound regularity on naming in French. Psychological Research, 53, 3-12.

Cormier, P., MacDonald, G. W., Grandmaison, E., \& Ouellette-Lebel, D. (1995). Développement d'un test d'analyse auditive en francais: Normes et validation de construit. Revue des Sciences de l'Education, 21, 223-240.

Cummins, J. (1984). Bilingualism and special education: Issues in assessment and pedagogy. Los Angeles: College-Hill Press.

Cummins, J. (1991). Interdependence of first- and second-language proficiency in bilingual children. In E. Bialystok (Eds), Language processing in bilingual children (pp. 70-89). New York: Cambridge University Press.

Cunningham, A. E., Perry, K. E., \& Stanovich, K. E. (2001). Converging evidence for the concept of orthographic processing. Reading \& Writing: An Interdisciplinary Journal, 14, 549568 .

Cunningham, A. E., \& Stanovich, K. E. (1991). Tracking the unique effects of print exposure in children: Associations with vocabulary, general knowledge, and spelling. Journal of Educational Psychology, 83, 264-274. 
Lafrance \& Gottardo: Study of phonological processing skills and reading

Cunningham, A. E., \& Stanovich, K. E. (1997). Early reading acquisition and its relation to reading experience and ability 10 years later. Developmental Psychology, 33, 934-945.

Cunningham, A. E., \& Stanovich, K. E. (1998). The impact of print exposure on word recognition. In J. L. Metsala \& L. C. Ehri (Eds.), Word recognition in beginning literacy (pp. 235-262). Mahwah, NJ: Erlbaum.

Cutler, A., Mehler, J., Norris, D., \& Segui, J. (1986). The syllable's differing role in the segmentation of French and English. Journal of Memory and Language, 25, 385-400.

DaFontoura, H. A., \& Siegel, L. S. (1995). Reading, syntactic, and working memory skills of bilingual Portuguese-English Canadian children. Reading and Writing: An Interdisciplinary Journal, 7, 139-153.

de Jong, P. F., \& van der Leij, A. (2002). Effects of phonological abilities and linguistic comprehension on the development of reading. Scientific Studies of Reading, 7, 51-78.

Denckla, M. B., \& Rudel, R. G. (1974). Rapid automatic naming of pictured objects, colors, letters and numbers by normal children. Cortex, 1, 186-202.

Durgunoglu, A. Y. (2002). Cross-linguistic transfer in literacy development and implications for language learners. Annals of Dyslexia, 52, 189-204.

Durgunoglu, A. Y., Nagy, W. E., \& Hancin-Bhatt, B. J. (1993). Cross-language transfer of phonological awareness. Journal of Educational Psychology, 85, 453-465.

Ehri, L. C. (1997). Sight word reading in normal readers and dyslexics. In B. Blachman (Ed.), Foundations of reading acquisition and dyslexia: Implications for early intervention (pp. 163189). Mahwah, NJ: Erlbaum.

Ehri, L. C. (1998). Grapheme-phoneme knowledge is essential for learning to read words in English. In J. L. Metsala \& L. C. Ehri (Eds.), Word recognition in beginning reading (pp. 3-40). Hillsdale, NJ: Erlbaum.

Frith, U. (1986). A developmental framework for developmental dyslexia. Annals of Dyslexia, 36, 69-81.

Gathercole, S. E., \& Baddeley, A. D. (1990). Phonological memory deficits in language disordered children: Is there a causal connection? Journal of Memory \& Language, 29, 336-360.

Geva, E., \& Siegel, L. S. (2000). Orthographic and cognitive factors in the concurrent development of basic reading skills in two languages. Reading and Writing: An Interdisciplinary Journal, 12, $1-31$.

Geva, E., \& Wade-Woolley, L. (1998). Component processes in becoming English Hebrew biliterate. In A. Y. Durgunoğlu \& L. Verhoeven (Eds.), Literacy development in a multilingual context (pp. 85-110). Mahwah, NJ: Erlbaum.

Geva, E., \& Wang, M. (2001). The development of basic reading skills in children: A cross language perspective. Annual Review of Applied Linguistics, 21, 182-204.

Geva, E., Yaghoub-Zadeh, Z., \& Schuster, B. (2000). Understanding individual differences in word recognition skills of ESL children. Annals of Dyslexia, 50, 123-154.

Gombert, J. E. (1992). Metalinguistic development. London: Harvester-Wheatsheaf.

Goswami, U. (2002). Phonology, reading development and dyslexia: A cross-linguistic perspective. Annals of Dyslexia, 52, 1-23.

Goswami, U., \& Mead, F. (1992). Onset and rime awareness and analogies in reading. Reading Research Quarterly, 27, 152-162.

Goswami, U., Ziegler, J., Dalton, L., \& Schneider, W. (2003). Nonword reading across orthographies: How flexible is the choice of reading units? Applied Psycholinguistics, 24, 235-247.

Gottardo, A., Stanovich, K. E., \& Siegel, L. S. (1996). The relationships between phonological sensitivity, syntactic processing and verbal working memory in the reading performance of third-grade children. Journal of Experimental Child Psychology, 63, 563-582.

Gottardo, A., Yan, B., Siegel, L. S., \& Wade-Woolley, L. (2001). Factors related to English reading performance in children with Chinese as a first language: More evidence of cross language transfer of phonological processing. Journal of Educational Psychology, 93, 530-542.

Gough, P. B., Ehri, L. C., \& Treiman, R. (Eds.). (1992). Reading acquisition. Hillsdale, NJ: Erlbaum.

Hatcher, P. J., Hulme, C., \& Snowling, M. J. (2004). Explicit phoneme training combined with phonic reading instruction helps young children at risk of reading failure. Journal of Child Psychology \& Psychiatry \& Allied Disciplines, 45, 338-358.

Hulme, C., Hatcher, P. J., Nation, K., Brown, A., Adams, J., \& Stuart, G. (2002). Phoneme awareness is a better predictor of early reading skill than onset-rime awareness. Journal of Experimental Child Psychology, 82, 2-28. 
Lafrance \& Gottardo: Study of phonological processing skills and reading

Jiménez-González, J. E. (1997). A reading-level match study of phonemic processes underlying reading disabilities in a transparent orthography. Reading and Writing: An Interdisciplinary Journal, 9, 23-40.

Juel, C. (1988). Learning to read and write: A longitudinal study of 54 children from first through fourth grades. Journal of Educational Psychology, 80, 437-447.

Kirby, J. R., Parrilla, R. K., \& Pfeiffer, S. L. (2003). Naming speed and phonological awareness as predictors of reading development. Journal of Educational Psychology, 95, 453-464.

Lesaux, N., \& Siegel, L. (2003). The development of reading in children who speak English as a second language. Developmental Psychology, 39, 1005-1019.

Lindsey, K. A., Manis, F. R., \& Bailey, C. E. (2003). Prediction of first-grade reading in Spanish speaking English-language learners. Journal of Educational Psychology, 95, 482494.

Lundberg, I., Frost, J., \& Petersen, O. (1988). Effects of an extensive program for stimulating phonological awareness in preschool children. Reading Research Quarterly, 23, 263-284.

Manis, F. R., Seidenberg, M. S., \& Doi, L. M. (1999). See Dick RAN: Rapid naming and the longitudinal prediction of reading subskills in first and second graders. Scientific Studies of Reading, 3, 129157.

Mann, V. (1984). Reading skill and language skill. Developmental Review, 4, 1-15.

McBride-Chang, C. (1995). What is phonological awareness? Journal of Educational Psychology, 87, 179-192.

McBride-Chang, C., \& Kail, R. V. (2002). Cross-cultural similarities in the predictors of reading acquisition. Child Development, 73, 1392-1407.

Morais, J., Alegria, J., \& Content, A. (1987). Segmental awareness: Respectable, useful, and almost always necessary. Current Psychology of Cognition, 7, 530-556.

Naglieri, J. A. (1985). Matrix analogies test—Expanded form. San Antonio, TX: Psychological Corporation.

Parrila, R., Kirby, J., \& McQuarrie, L. (2004). Articulation rate, naming speed, verbal short-term memory, and phonological awareness: Longitudinal predictors of early reading development? Scientific Studies of Reading, 8, 3-26.

Paulesu, E., Démonet, J.-F., Fazio, F., McCrory, E., Chanoine, V., Brunswick, A., et al. (2001). Dyslexia: Cultural diversity and biological unity. Science, 291, 2165-2167.

Perfetti, C. A. (1985). Reading ability. New York: Oxford University Press.

Plaut, D., McClelland, J., Seidenberg, M., \& Patterson, K. (1996). Understanding normal and impaired word reading: Computational principles in quasi-regular domains. Psychology Review, 103, $56-115$.

Rack, J., Hulme, C., Snowling, M., \& Wightman, J. (1994). The role of phonology in young children learning to read new words: The direct mapping hypothesis. Journal of Experimental Child Psychology, 57, 42-71.

Rosner, J., \& Simon, D. P. (1971). The Auditory Analysis Test: An initial report. Journal of Learning Disabilities, 4, 40-48.

Schneider, W., Roth, E., \& Ennemoser, M. (2000). Training phonological skills and letter knowledge in children at risk for dyslexia: A comparison of three kindergarten intervention programs. Journal of Educational Psychology, 92, 284-295.

Seidenberg, M. S., Waters, G., Barnes, M., \& Tanenhaus, M. K. (1984). When does irregular spelling or pronounciation influence word recognition? Journal of Verbal Learning \& Verbal Behavior, $23,383-404$.

Service, E. (1992). Phonology, working memory, and foreign-language learning. Quarterly Journal of Experimental Psychology: Human Experimental Psychology, 45A, 21-50.

Seymour, P. H. K., Aro, M., \& Erskine, J. M. (2003). Foundation literacy acquisition in European orthographies. British Journal of Psychology, 94, 143-174.

Shankweiler, D., Crain, S., Brady, S., \& Macaruso, P. (1992). Identifying the causes of reading disability. In P. B. Gough \& L. C. Ehri (Eds.), Reading acquisition (pp. 275-305). Hillsdale, NJ: Erlbaum.

Share, D. L. (1995). Phonological recoding and self-teaching: Sine qua non of reading acquisition. Cognition, 55, 151-218.

Share, D. L., \& Stanovich, K. E. (1995). Cognitive processes in early reading development: Accommodating individual differences into a mode of acquisition. Issues in Education: Contributions from Educational Psychology, 1, 1-57. 
Lafrance \& Gottardo: Study of phonological processing skills and reading

Snow, C. E., Burns, M. S., \& Griffin, P. (Eds.). (1999). Preventing reading difficulties in young children. Washington, DC: National Academy Press.

Sprenger-Charolles, L., \& Casalis, S. (1995). Reading and spelling acquisition in French first graders: Longitudinal evidence. Reading and Writing: An Interdisciplinary Journal, 7, 3963.

Sprenger-Charolles, L., \& Siegel, L. S. (1997). A longitudinal study of the effects of syllabic structure on the development of reading and spelling skills in French. Applied Psycholinguistics, 18, $485-505$.

Sprenger-Charolles, L., Siegel, L. S., \& Bonnet, P. (1998). Reading and spelling acquisition in French: The role of phonological mediation and orthographic factors. Journal of Experimental Child Psychology, 68, 134-165.

Stanovich, K. E., Cunningham, A. E., \& Cramer, B. B. (1984). Assessing phonological awareness in kindergarten children: Issues of task comparability. Journal of Experimental Child Psychology, $38,175-190$.

Stanovich, K. E., \& Siegel, L. S. (1994). The phenotype performance profile of reading disabled children: A regression-based test of the phonological-core variable-difference model. Journal of Educational Psychology, 86, 24-53.

Stuart, M., \& Coltheart, M. (1988). Does reading develop in a sequence of stages? Cognition, 30, 139-181.

Torgesen, J. K., Wagner, R. K., Rashotte, C. A., Burgess, S. R., \& Hecht, S. A. (1997). Contributions of phonological awareness and rapid autonomic naming ability to the growth of word-reading skills in second- to fifth-grade children. Scientific Study of Reading, 2, 161-185.

Treiman, R., Mullennix, J., Bijeljac-Babic, R., \& Richmond-Welty, D. (1995). The special role of rimes in the description, use, and acquisition of English orthography. Journal of Experimental Psychology, 124, 107-136.

Venezky, R. L., \& Massaro, D. W. (1987). Orthographic structure and spelling-sound regularity in reading English words. In A. Allport, D. MacKay, W. Prinz, \& E. Scheerer (Eds.), Language perception and production (pp. 159-179). London: Academic Press.

Wade-Woolley, L. (1999). First language influences on second language word reading: All roads lead to Rome. Language Learning, 49, 447-471.

Wade-Woolley, L., \& Geva, E. (2000). Processing novel phonemic contrasts in the acquisition of L2 word reading. Scientific Studies of Reading, 4, 295-311.

Wagner, R. K., \& Torgesen, J. K. (1987). The nature of phonological processing and its causal role in the acquisition of reading skills. Psychological Bulletin, 101, 192-212.

Wagner, R. K., Torgesen, J. K., Laughon, P., Simmons, K., \& Rashotte, C. A. (1993). Development of young readers' phonological processing abilities. Journal of Educational Psychology, 85, 83-103.

Wagner, R. K., Torgesen, J. K., \& Rashotte, C. A. (1994). Development of reading-related phonological processing abilities: New evidence of bidirectional causality from a latent variable longitudinal study. Developmental Psychology, 30, 73-87.

Wagner, R. K., Torgesen, J. K., \& Rashotte, C. A. (1999). Comprehensive test of phonological processing. Austin, TX: PRO-ED Inc.

Wang, M., \& Geva, E. (2003). Spelling acquisition of novel English phonemes in Chinese children. Reading and Writing: An Interdisciplinary Journal, 16, 325-348.

Wechsler, D. (1991). Wechsler Intelligence Scale for Children-Third edition. San Antonio, TX: Psychological Corporation.

Wimmer, H. (1993). Characteristics of developmental dyslexia in a regular writing system. Applied Psycholinguistics, 14, 1-33.

Wimmer, H., Mayringer, H., \& Landerl, K. (1998). Poor reading: A deficit in skill automatization or a phonological deficit? Scientific Studies of Reading, 2, 321-340.

Woodcock, R. W. (1987). Woodcock Reading Mastery Tests—Revised: Examiner's manual. Circle Pines, MN: American Guidance Service.

Yopp, H. K. (1988). The validity and reading reliability of phonemic awareness tests. Reading Research Quarterly, 23, 159-177.

Ziegler, J. C., Perry, C., \& Coltheart, M. (2003). Speed of lexical and nonlexical processing in French: The case of the regularity effect. Psychonomic Bulletin \& Review, 10, 947-953. 